Type of the Paper (Article)

\title{
System Design and Data Governance for Environmental Disaster Management in Smart Scenic - a case study of Huangshan Moutain
}

\author{
Zhong Wang ${ }^{1}$, Zhenjie Liao' ${ }^{2}$ Lijuan Zhang ${ }^{2 *}$ \\ ${ }^{1}$ Zhong Wang, an Professor at the Guangdong university of technology, China. Email: wz.0@hotmail.com. \\ ${ }^{2}$ Zhenjie Liao, a lecturer at the Department of Business Administration, Guangzhou huashang college, China.E- \\ mail:liaozhenjie_2002@163.com. \\ ${ }^{2}$ Lijuan Zhang, a lecturer at the Department of Business Administration, Guangzhou huashang college, China.E- \\ mail:281746568@qq.com. \\ *Correspondence:281746568@qq.com; Tel.: 86+13450476690
}

\begin{abstract}
Intensity of natural and man-made disasters is increasing day by day. Disaster is one of the major threats that affects the sustainable development of tourist attractions. Big data and Internet of Things(IoT) will greatly improve the disaster management. Based on the Big Data and IoT, a tourism attraction disaster management system is designed, divided into several stages namely pre-disaster early warning prevention, disaster mitigation, recovery and reconstruction after disaster and updating disaster planning. Then, the system flow is analysed, as well as the system structure is constructed. Additional, system function and its operation flow are introduced, including disaster warning, disaster relief, disaster assessment, real-time monitoring and supporting disaster planning functions. Finally, an application case is introduced. Research intends to improve tourism area disasters management.
\end{abstract}

Key words: Smart Scenic; environmental disasters management; organization transformation; system design; Big Data; Internet of Things

\section{Introduction}

Disasters are the most vulnerable factors which are affecting the human life and environment. With the rapid development of national economy, the rapid advance of urbanization and the change of climate and environment, all kinds of environmental disasters, such as geological disasters, floods and droughts, environmental pollution disasters and ecological damage disasters, occur frequently, causing huge casualties and economic losses, seriously endangering people's lives and restricting the sustainable development of economy. Many well-known scenic spots always attract huge crowds of people. At present, the management of environmental disasters in most scenic spots of China is still at a low level, and there is no pre disaster evaluation and emergency management system. Therefore, once a disaster occurs, which would cause great loss to both tourists' life and property, heavily damaged the development of local tourism and brought a destructive influence in a long period of time(Y. Liu, Cheng, \& Ouyang, 2019). More and more scenic spots are interested in disaster 
management systems, but how to conduct system design and data governance are still being explored.Therefore, it is necessary to establish an integrated environmental disaster database management, evaluation and emergency response system.

Data governance was initially explored and practiced throughout the industries, which initially refers to a collection of activities that exercise power and control over data assets, including subject, time, context, type of activity, and method of implementing these activities. Academics have also conducted extensive discussions on data governance, which is, for instance, a collection of processes, standards, and policies involved in enterprise management information assets (Alhassan, Sammon, \& Daly, 2018). These concepts are positive factors to relating to the pursuit of enterprise data quality. Big data has extended the data governance's connotation, highlighting data optimization, privacy protection, and data monetization in big data resource utilization (Johnson, Friend, \& Lee, 2017). Meanwhile, managers face data cleansing, governance, and their related management issues (Chen et al., 2013; Church \& Dutta, 2013), requiring enterprises to implement a new series of governance policies to make full use of big data resource (Wang, Kung, \& Byrd, 2018). Implementing a robust big data governance project becomes a requisite (Al-Badi, Tarhini, \& Khan, 2018).

This paper fulfills the two research gaps mentioned above by applying a case study, uncovers the formation and mechanism of data governance to promote efficiency of disaster management system. The next sections present the literature review concerning the theoretical fundamentals and main variables, and descriptions of the data and methods. Our results follow this, and we conclude with a discussion of our findings and implications for future research.

\section{Literature}

It is significant to research how to relieve the influence of tourists attractions' natural disasters and realize the sustainable development of tourism(Lee, 2019). The research about the environmental disasters management of tourism attractions started earlier and owned many important relevant literatures. Main contents are as follow:

(1) tourism disaster management. While the travel and tourism industry is increasingly exposed to natural disasters(Rittichainuwat, 2011), some studies have examined crisis management in the tourism context. These researches targeted business operators and the local government, discussing the response plan and the recovery method from the emergency strategy and the marketing point(Racherla $\& \mathrm{Hu}, 2009$ ). additionally, there are a number of studies on the risk of tourism disaster, but mainly focusing on disaster factors, such as rainfall(Gómez Martín, 2005), storms(Méheux \& Parker, 2006). There are also some researches from the perspective of technology and information systems on natural 
disaster management in tourist destinations(Estevo \& Costa, 2020; Ha, 2020).

(2) disaster risk management. Until recent years, the research on disaster risk assessment and management of scenic spots has come into scholars' view. These researches mainly focus on the management mechanism and the model construction, for example, Maria(2012) applied a risk management model to identify risks for Romanian travel agencies and proposed a risk management model in tabular format(Oroian \& Gheres, 2012). In addition, many articles aimed on the seismic risk management, due to its grave threat to the tourism and tourists' psychological(Orchiston, 2012).

(3) government responsibilities in the disasters of tourists attractions. Besides these, there are a lot of researches about the stakeholders in the tourism market of the crisis events, such as visitors' perception and behavior analysis (Avraham, 2016), tourism business owners (Hystad \& Keller, 2008) and local residents (Gurtner, 2016; Kellens, Zaalberg, Neutens, Vanneuville, \& Maeyer, 2011),such as the study on the damage and countermeasures of natural disasters, crisis management about the tourism(Ritchie, 2004), environmental disasters management(Tsai \& Chen, 2011) etc. However, the study on environmental disasters management of tourists attractions are relatively backward.

Most of current literatures focus on the specific disasters, or disaster reduction of tourists attractions, as well as government responsibilities in the disasters of tourists attractions. It's insufficient to study the environmental disasters management in tourists attractions combined with the current advanced information technology. Therefore, this thesis, viewed from a systematology standpoint, constructs the system structure based on Big data and IoT( the Internet of Things) (Conti, 2006; Gershenfeld, Krikorian, \& Cohen, 2004)to improve tourism area disasters management.

(4) Key technology in tourist attractions

Most tourists attractions are located in the far, dangerous and beautiful places. Travelers come here afar especially, not familiar with the environment around. As a result, it is rather dangerous once the disasters come(Chan, Nozu, \& Cheung, 2019). However, currently, the environmental disasters management of tourists attraction mainly depends on the traditional manual mode. This mode is slow in speed and low in quality when receiving and delivering messages. On the one hand, it is hard to forecast the disasters exactly and effectively, on the other hand, when disasters occur, rescues cannot be reached in the first time and after the disaster, reconstruction and recovery only depend on the previous experience(Chan, Nozu, \& Zhou, 2020), also cannot make full preparations for the next disasters.

In short, the standard of the current management of the disaster area is not high, in the event of a disaster, whether it is natural or social, the devastated area will face the fact of closure which will restrict the sustainable development of the area. It is necessary to adopt the advanced information 
technology to improve the level of the management.

(1)big data

Big data is a term for data sets that are so large or complex that traditional data processing applications are inadequate to deal with. The powerful advantage of big data is that combines all kinds of data perfectly, including Internet, spatial information, finance, urban informatics, and business informatics, which can study the changes in space and time and conduct predictive analytics, user behavior analytics, or certain other advanced data analytics. Using big data to management and analysis of spatial data, the result can be visualized, which provides a very important technology for disaster prediction, forecasting and management $\left(\mathrm{J}^{\cdot 2}\right.$ nior, Rodrigues, \& Scoton, 2009; Wang, Yao, Chen, \& Chen, 2011). In addition, big data can also be associated with some combination of technology and features, such as the GIS, RS (Remote Sens ), GPS (Global Positioning System) software, which can provide a guide platform to manage the overall situation of the disaster area.

Big data has important application value in the tourist area. For example, through real-time access to the scenic flow each minute, calculation and prediction of the population distribution and density can be accurate. By comparing the thermal map with the satellite map, we can estimate the number of custom, thus issue early warning and flow guidance(Filimonau \& Coteau, 2019). Additionally, through big data analysis, to achieve passenger statistics, consumption analysis, consumer forecasts, traffic warning, source market expansion, decision support.

(2) IoT

At starting of the Internet of Things (IoT), it is passing around a world, in which diverse kinds of different objects are there connected to the Internet. It contains the use of smart phones, sensors, cameras, and other devices to make over the actions of people and things into data and link it to the Internet. With its capability to model the real world in digital form and accomplish scrutiny and replication in cyberspace, the IoT is able to reveal new value at an unparalleled rate and deliver it as response to the real world. What's more, IoT is a beneficial compelement. Different definitions for the IoT have appeared and the term is evolving as the technology and implementation of the ideas move forward. Which reachs a consensus, IoT is an integrated part of Future Internet and could be defined as a dynamic global network infrastructure with self configuring capabilities based on standard and interoperable communication protocols where physical and virtual 'things' have identities, physical attributes, and virtual personalities and use intelligent interfaces, and are seamlessly integrated into the information network.

RFID and sensors embedded in tickets, vehicles, buildings, roads, trees, etc., can real-time access flow of people, traffic, weather and other information to support decision-making for the scenic. IoT 
has a comprehensive, automatic and timely perception to the scenic infrastructure, services, facilities, geography, natural resources, tourist behavior, personnel traces. Through the electronic ticketing, electronic payment, access control, vehicle induction, positioning navigation, voice navigation, trajectory tracking, information push, IoT can support the realization of mobile Internet visitors services. Through intelligent dispatch, emergency plans, security monitoring, central large screen, passenger control, LED release, IoT can conduct dynamic visual security management.

\section{System Flow}

With the rapid development of tourism, the types, forms, causes and changing patterns of the scenic disaster become more and more complex, bringing more and more losses for the society, environment and people. This makes the work of disaster management become increasingly complex. Nevertheless, the process of the management of the disaster area has clear stages. Specifically, it can be divided into several stages, namely pre-disaster early warning prevention, disaster mitigation, recovery and reconstruction after disaster and updating disaster planning. They form a cycle of information management(Goossen, Meeuwsen, Franke, \& Kuyper, 2009). Brent gives the strategic management framework and its flow chart provided by the system(Chang \& Caneday, 2011) of the disaster area. Based on the GIS platform,this passage gives the management system processes of the disaster area, which is shown in Figure 1.

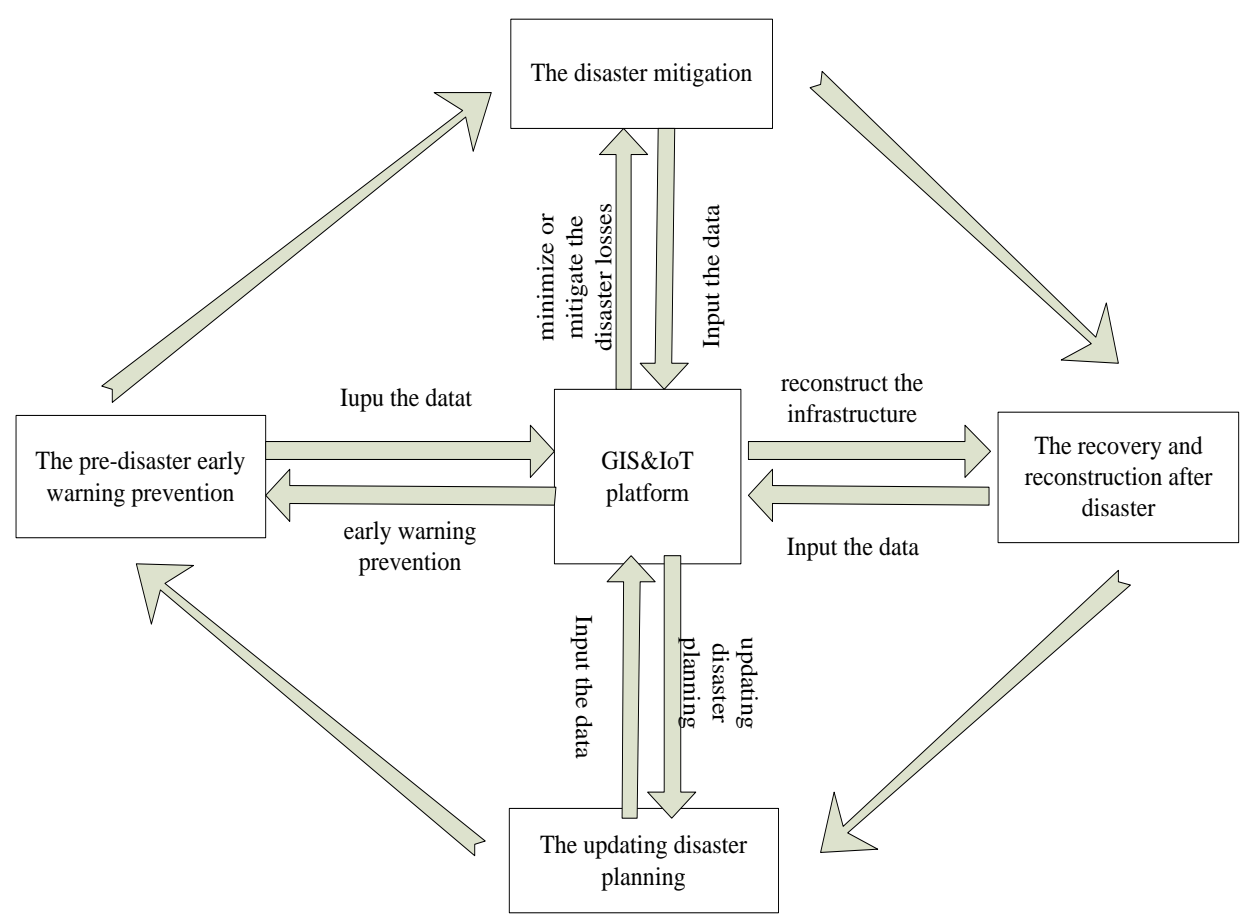

Figure 1 Tourism Area disaster management system flow

(1)The pre-disaster early warning prevention. 
This stage mainly input monitoring data of the IoT sensor, dynamic data of the RS and the historical data into the system, through advanced forecasting methods, analyzing the time, location, and the probability and the damage to life, property and the environment of the disaster area, thus lying foundation for future mitigation, response, recovery and reconstruction. Once the system predict the potential disaster, the institution of the area management should design disaster prevention and mitigation plans based on the forcast result. In addition, the system can also be used to do the relief exercise in the stage of pre-disaster, using GIS showing the location of the disaster, preparing emergency material, equipment, designing the transport routes, rescue personnel distribution and the announcement to the public, planning the evacuation routes and so on.

(2)The disaster mitigation.

This phase take the advantage of and the system to analyse and process the data to determine the casualties and infrastructure destruction within the area. At this point, a variety of data can be used. In addition to IOT, RS, GPS, the phone's location information, social media data can also be applied for big data analysis. The affected community residents and visitors will be taken appropriate measures to rescue; The infrastructure and tourism resources will be protected in order to minimize or mitigate the disaster losses. At the same time, to appease the affected staff, to make the disaster situation stable and to take measures to reduce the probability of the disaster-related derivatives.

(3)The recovery and reconstruction after disaster .

The main work of this stage is to restore and rebuild the disaster area. To combine the GPS and RS technology to determine the extent of disaster damage, we must first restore critical facilities and systems, such as food and water supply(Shurland \& Jong, 2008). The reconstruction requires that both the hardware and the software should be reconstructed. The reconstruction of hardware is to reconstruct the infrastructure and the related project. The reconstruction of software is the reconstruction of the scenic image. It is very important to let the tourists get out from the shadow of the disaster area and to give visitors the signal of safety in order to attract tourists.

(4)The updating disaster planning.

This phase can be divided into two cases. When there is no disaster planning in the disaster area, the system will analyse and process the disaster-related data, the sub-aid management agency will distribute the resources, equipment and staff(Jones, 2016). When there is disaster planning in the disaster area, there will be some adjustment to the previous planning and also the original plan will be revised and updated based on the new data. 


\section{Systematic structure}

we need a module type of planning to make the tourism scenic spot work in computer. Based on GIS platform, it can be divided into the following specific modules, according to systematic tasks and concrete target (As shown in figure 2 ):

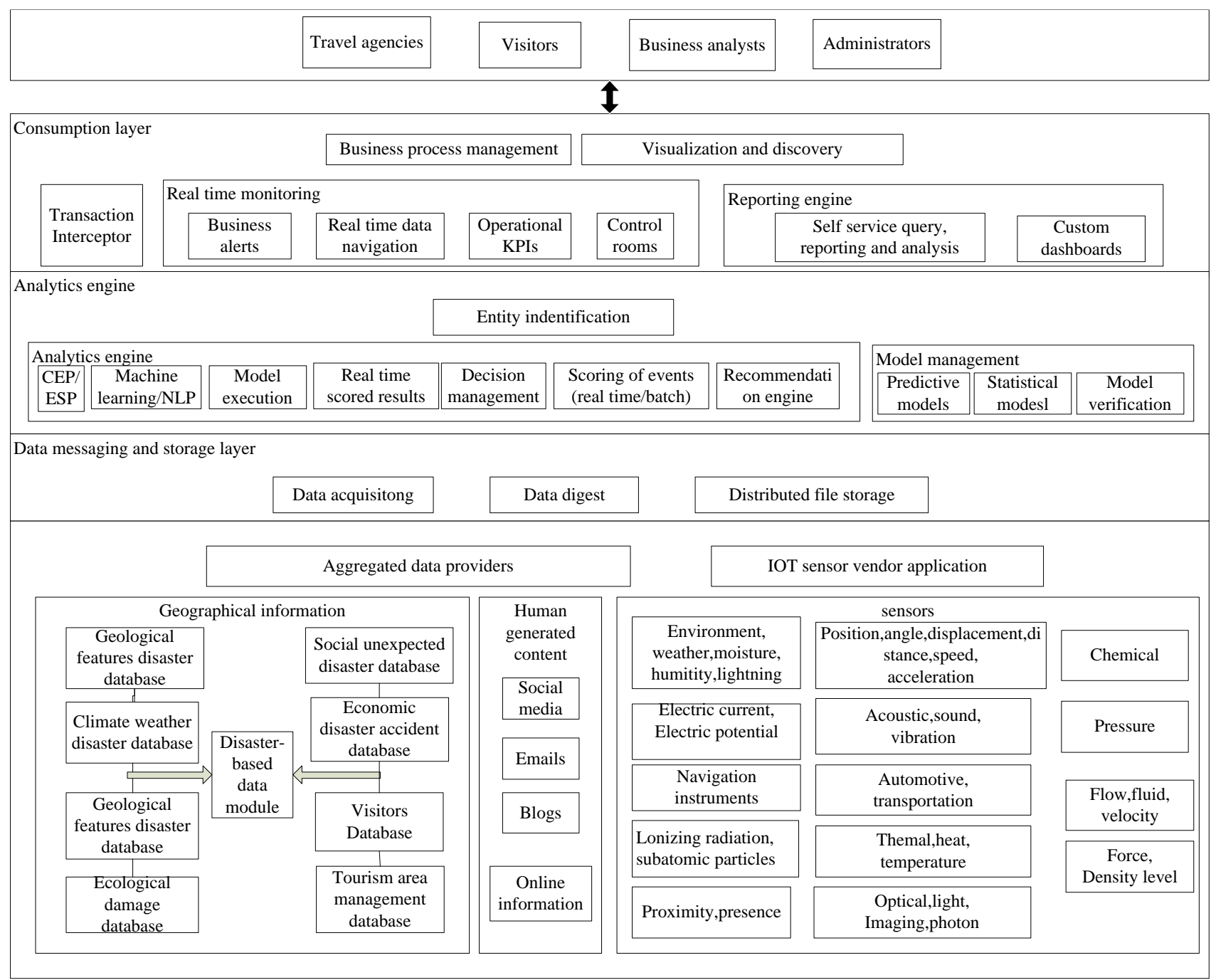

Figure 2 Tourism Area disaster management system structure

(1) Systematic control module

Systematic control module, the master control module, is used for communication between users and system, which is made up of the user interface, the systematic environment and information administrative subprime module. We should design a friendly interface to guide users into data system, in order that they can implement the relevant operation according to the specific task in subprime module(Jia, Shi, Jia, \& Li, 2012).

(2)Input module

Input module puts all kinds of basic data into the master control module, mainly including two son 
modules: data input module and graphic input module, because the data is not only made up of text, but the figure, graphics, video, etc. This module is made up of several subprime modules such as equipment initialization, graphic vectorization, the graphic data conversion and videos operation.

(3)Basic data module

This module mainly consists of various disaster database in the tourism scenic spot. Disasters , which generally appear in scenic spot, are mainly geological and morphological tourist disasters (volcano, earthquake, landslide, collapse, debris flow, etc.), the climate weather tourist disasters (typhoon, snowstorm, dust storms, etc.), the economic and social changes (war, disaster at home and abroad, and political change economic crisis, the exchange rate, etc.), social life accident (plague, fire, traffic accidents, etc.), and the ecological environment destruction disasters (environment pollution, tourism resources destruction, etc.). Therefore, basic data module is mainly made up of the database related with disasters(Stanganelli, 2008). As for specific database in the system, it depends on the scenic spot. In addition, tourists database and scenic spot management database also should be included in a complete GIS system.

(4)Editing and processing module

This module is mainly used to realize human-machine mutual compiling. Users can retrieve quickly, edit and update the basic data module, according to their own needs.

(5)intelligence analysis module

This module calls for all levels of modules, to analyze different specific task systematically, intelligently and automatically. Then it estimates and simulates the results. For example, it can simulate, predict the possibilities of the meteorological disasters according to the changing index of air temperature, then it puts forward prevention countermeasures.

(6)Output module

This module consists of many subprime module such as graphic output, data output and data conversion, realize the information of multi-medium and multi-type output.

\section{The realization of the system function}

There are many kinds of disasters in tourists areas which include natural calamities and human destruction. What's more, the tourists areas are facing much more complicated disaster management work due to the large amount of population and most tourists are unfamiliar with the environment(Paraskevas \& Altinay, 2013). The establishment of disaster management system is to improve the level of disaster management through the superiority of big data. The disaster management of tourists areas can complete many kinds of functions based on big data, which mainly contain early 
warning, provide disaster relief, disaster evaluation and monitoring. The realization of those functions is as follow:

\section{1 early warning}

Many disasters in tourists areas cannot be avoided by people such as earthquake, volcanic eruption etc. but all those can reduce the losses through the establishment of early warning system, which is one of the main purposes of disaster management. The realization of early warning should be related with many apartments which both need the distribution of computer and the coordination of management system.(1) in the aspect of computer system, people should establish early warning system, which faces to intense tourists disaster, based on ArcIMS and NET. First, design a method of integration modelbase, expert knowledge base, information processing technique and big data, and then, public, register and offer to consumers through describing WSDL to Web. In this way, the system can realize the information sharing with all kinds of related consumers under incidents, which can improve the timeliness, sensitivity and decision efficacy of early warning(Mikulić, Sprčić, Holiček, \& Prebežac, 2016).(2) in the aspect of administration, it need information, resource and service cooperation among departments which could adjust at any time. Therefore, early warning system is able to realize information sharing among each department, and take mulitdivisional action immediately.

\section{2 function of relief}

The system should play an important role in the function of relieving and reducing the disaster when it occurs, which is the core function in the area of disaster management system. The function is realized through the following processes ( shown as figure 3):

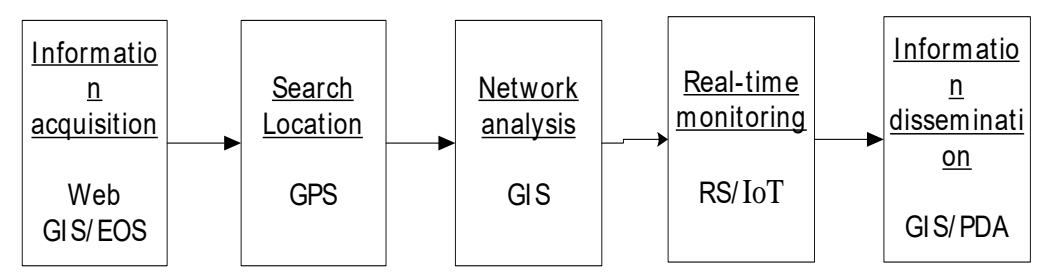

Figure 3 system flow chart of disaster relief

(1) Information acquisition

We can obtain information, then transfer it, process it, utilize and release it with the aid of the WEBGIS and EOS (GRS). Then we make comprehensive analysis on the data derived from different types of spatial data networks. Finally, we will know details about the disaster well on the basis of the analysis result so that we can offer suggestions for the command scheduling and decision-making.

(2) Search and location 
Initially, the current position of public emergency facilities (such as fire fighting, rescue and communications vehicles) and resources should be displayed in real time, so that the scenic spot administration department distributes and dispatches them effectively(B. Liu, Pennington-Gray, \& Krieger, 2016). The next, the disaster location should be located with the help of GPS in systematic charts, making the spatial localization and search available. In this way, we would realize the fast response, rapid search and rescue during the disaster.

(3) Network analysis

With the aid of the GIS network analysis functions, we need to develop the best rescue and evacuation route for the victims and relief resources to improve the rescue efficiency and minimize the losses caused by disasters. For example, in the network chart, the system will automatically display the shortest path length and the name of the best rescue route when we select a start node (assuming the ambulance ) and the end (assuming the trapped tourists ).

(4) Real-time monitoring

With the aid of RS technology, the disaster should be monitored by the means of multi-directional, multiple time periods and mulit-band real-time and monitored by video, combined with the technology of real-time online and connected with the system for tracking and reporting of disaster's spreading and changing circumstances. It facilitates its timely rescue and disaster reduction, such as searching and rescuing, providing medical services, cutting off the polluted water and isolating the hazardous areas.

(5) Information release

During the relief process, information should be oriented at not only the area of the public, but also the victims and rescuers. For the public out of the spot, the state and changes of statistical information should be released regularly or irregularly through information release agent services; and we should do this work rigorously, because victims in disaster are susceptible. Under the pressure of disaster, information's content and form should be simplified and easy to understand, and it should be made clear in a short time(Ashworth \& Page, 2011). Therefore, we should use the PDA (personal digital assistant) and similar rescue equipment as far as possible to release the best graphics and image information with a smaller file data, so as to improve rescue efficiency and minimize the losses.

\subsection{Damage assessment function}

Dynamic evaluation of damage is an important part of the disaster management system .As the important basis of disaster prevention, mitigation, relief and reconstruction for decision-making, this function runs throughout the entire process of the disaster management. 
According to the different phases of the disaster and the process, the disaster dynamic assessment can be divided into 3 types: pre-disaster assessment in advance, follow-up evaluation in disaster and post-disaster study.

The realization of dynamic evaluation function in disasters depends on reliable data sources and scientific assessment method. As to the data, the system can provide the relevant aspects of vector data, video data, DEM data, project data and statistics, etc.; as to the evaluation method, the system can make a secondary development of GIS, and design evaluation procedures, and do the dynamic evaluation of disaster, providing the foundation for decision-making.

The dynamic evaluation function gives expression in the following concrete aspects:

(1) pre-disaster assessment in advance

The decision of disaster prevention and reduction, made by disaster administration section, is supported and served by building the model of potential disaster events and evaluating and predicting the area, the scope and the result of various loss, referring to historical data and using a certain intelligence analysis method.

(2) follow-up evaluation in disaster

In order to make the disaster administration section and decision makers can respond quickly to disasters and make scientific decisions, it should use monitoring system to have the scope of the disaster as well as the destroy degree of the surrounding community, residents, tourism resources and environment in hand, then make dynamic assessment on various losses.

(3) Post-disaster study

The disaster management departments counts and evaluates the direct or indirect loss in the environment, human and material caused by the disaster by means of relevant GIS and RS technology, according to the relevant disaster report, the actual investigation and the other information resource.

\subsection{Real-time monitoring function}

It provides the scientific basis for decision-making , combining RS technology with GIS technology, MIS technology and network technology, etc. It is targeted at the whole scenic spot in order that disaster prevention management system will monitor the changes in spot dynamically.

The system mainly can achieve the following monitoring :

(1) Ecological environment monitoring

The system can monitor the geological structure, vegetation coverage and the change of the water in real time, preventing all kinds of natural disasters.

(2) Tourists monitoring 
For larger scenic areas, the system can monitor the special visitors (such as the old and children) or black spot to be on the safe side of the tourists.

(3) Building and the construction project monitoring

The system can monitor all kinds of buildings and various construction activities, especially some major construction projects, such as railway, highway, cableway, cable car, the station, warehouse, hospital, large scale culture sports and recreation facilities, the hotel building, water conservancy project, etc.

\subsection{Auxiliary disaster planning functions}

Countries thriving in tourism paid attention to the disaster planning in scenic spots while establishing tourism planning years ago, especially in famous scenic spot(Cassedy, 1991). By contrast, our country is relatively backward in this respect. The strong function of space database management and space analysis module, which belong to GIS, can assist disaster planning by the means of processing the related information.

The specific methods are as follows :

(1) Measuring each disaster damage index

It asks for installing grids in a certain proportion in the scenic spot. Then analysis the maximum loss points of each grid according to the basic data module, and translate it into damage index. For example, an ancient building is easily damaged, we should set a higher earthquake damage index.

(2) Comprehensive damage index calculation

Aggregate all kinds of layers of potential disaster damage index on the basis of GIS spatial analysis. Finally, we can obtain the comprehensive damage index of each grid in the scenic spot by the means of weighted average.

(3) Functional partition

Plan the division with GIS system according to the comprehensive damage index of each grid. Layout resources and equipment, configure patrol staffs, confirm patrol protection point, and implement disaster planning on the basis of the disaster area chart.

\section{Application Case}

Huangshan, located in Anhui Province, China, is a heritage of world nature and culture. It's a world geological park. In 2019, among the top 100 smart travel scenic spots launched by China Internet Weekly, Huangshan Scenic Area ranked the 19th. Won the first place in all mountain scenic spots. All along, Huangshan Scenic Area has been devoted to the construction of smart tourism. It has innovated 
the tourism management mode by applying technologies such as Internet of Things, cloud computing, mobile internet and big data processing to the public information services of tourists, the management of tourism industry and the development of tourism industry. Service mode, not only to achieve the intelligent management of scenic spots, but also allow tourists to personally feel the wisdom of the construction of tourism convenience and comfort (see Figure 4).
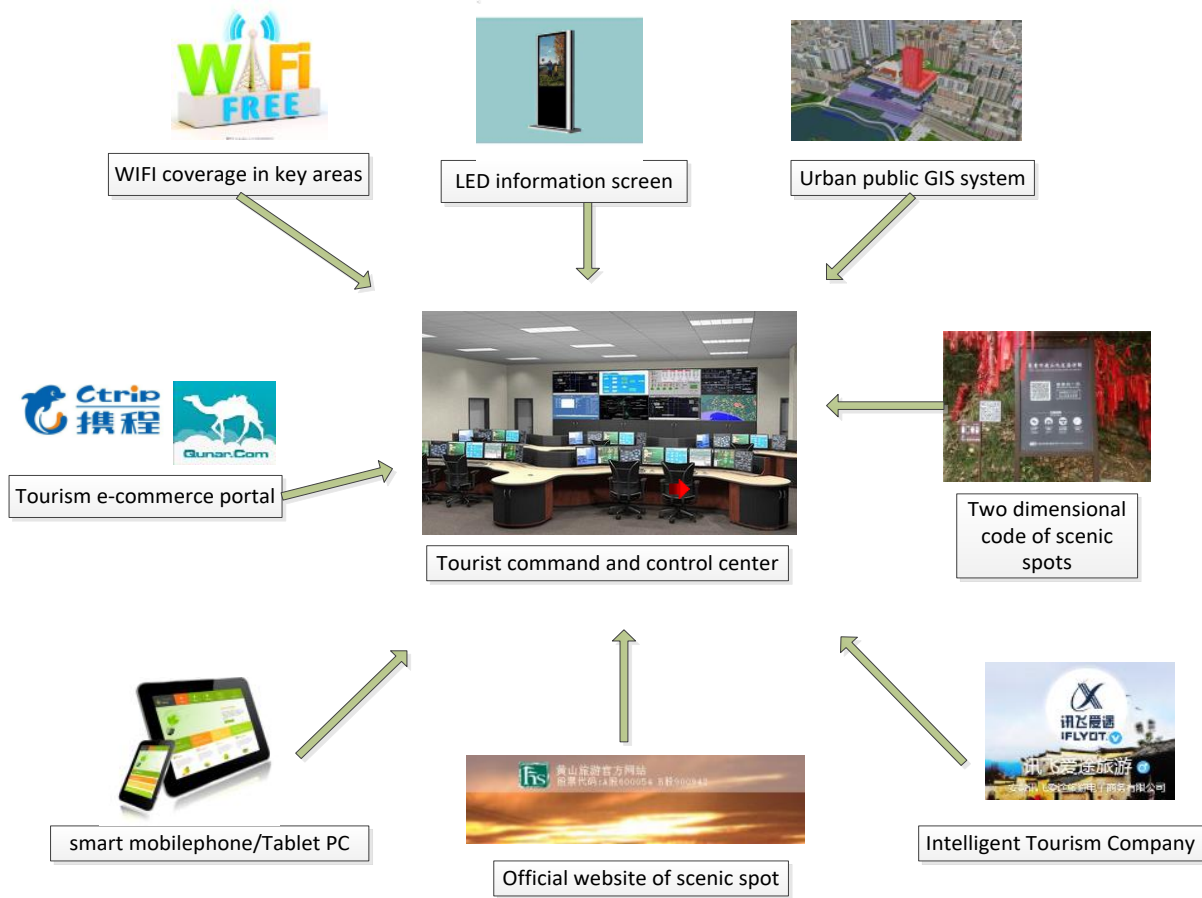

Figure 4 General framework map of Mount Huangshan intelligent scenic spot

(1) launched a strategic cooperation with the E-commerce company. Moved offline products to online. Since 2013, six tourism e-commerce platforms such as Huangshan Tourism and Ctrip, Qunar, Tongcheng, ELong, Lvmama and Tuniu have launched strategic cooperation successively through marketing, online sales, opening flagship stores, thematic promotions And other ways, and actively expand marketing channels, the offline product moved to the online, promoting the integration of online and offline development.

(2)Cooperate with IFLYTEK, build "one-stop" convenient service platform. In April 2015, Huangshan Tourism and IFLYTEK signed a joint venture framework agreement to set up a joint venture company focusing on smart tourism. It mainly provides tourist services, electricity supplier services and credit certification services to tourists and tourism enterprises. through the app,visitors can personally enjoy the interactive, sharing, entertainment, social networking, e-commerce and other services, not only help visitors have a comfortable traveling and sucure purchase experience, and provide a better travel experience for tourists. It also provides a series of related industry data analysis 
for the government administrative departments.

(3)In order to provide tourists with a full range of personalized travel services, Huangshan Tourism built a new media platform for Weibo, WeChat, Sohu and Huangshan Tourism APP. Food, hospitality, travel, visit, shopping entertaining are included in a network. At the beginning of 2011, Huangshan took the lead role in opening the official weibo in the scenic area of China and established "Official Website of Weibo for Huangshan Tourism" . Attracted 28 members in two years. "Huddle" provides tourists with all kinds of information and consulting services. In 2013, Huangshan Tourism opened the official WeChat and passed the certification in 2014, with more than 100,000 following. The comprehensive influence in Weibo and Wechat ranked the forefront of the national scenic area so far. In 2015, Huangshan Travel Sohu Client and Huangshan Tourism Android APP successively went out, which marked the completion of Huangshan Tourism New Media Platform. In 2016, Huangshan launched a more complete app called "Graceful Huangshan District" , which includes several sections such as "Enjoy Huangshan District", "Dynamic News", "Visit Huangshan in a map" and "Recommended Routes". Later, APP will gradually open up more and practical travel functions such as reservation payment and scenic spot explanation so that tourists can enjoy the happy experience brought by "Wisdom Travel".

(4)In 2014, Huangshan Tourism fully promoted to upgrade the entrance guard, which brought great convenience for tourists. After that, determined the second-generation ID card as the only online booking entrance. achieved the rapid clearance of mobile phones and financial IC card, becoming the first scenic spot which is able to achieve mobile finance and financial IC card clearance. Visitors can use the financial IC card electronic cash credit card gates on the gate, you can also use the phone online booking, clearance user binding, instead of the traditional paper tickets, without queuing tickets.

(5)In response to the demand for free exercise and individual travelers, Huangshan Tourism has added 15 automatic ticket machines at four box offices. Ease the pressure on ticketing of artificial windows during peak hours and reduce the waiting time for tourists to queue up for tickets. Key nodes such as cableways and other public areas have opened free wireless Network, set up mobile phone charging station to meet the needs of guests, to ease the pressure of tourists queuing psychological pressure; build two-dimensional code information platform, innovative navigation mode, visitors use the phone built-in scanning software scanning scenic area installed two-dimensional code identification plate, visitors can experience scenic attractions, tourist guides, tourist services and other functions, and effectively improve the tourist comfort.

(6)LED screens in huangshan display the number of people in the mountain, as well as sunrise, sea of clouds probability, so that tourists fully understand the information, arrange reasonable tourist routes; 
In peak period, implement "three pre-regulation" mechanism, scientific control the number of people, balance tourist attractions reception volume, to achieve browse in a different time, effectively protect the quality of tourism reception.

\section{Conclusion}

Collaboration of IoT and Big Data Analysis in Disaster management environment is an effective technique which can be practiced for ensuring automated and efficient management with less time. This paper puts forward the advice of building the disaster management system based on the platform of big data and IoT. It analyses the system procedure, builds the system structure and puts forward five methods of early warning system, disaster relief, disaster assessment, disaster planning and the supplementary of the disaster planning. China has several typical cases, such as Wuyi Mountain in Fujian Province, combined with big data from Baidu LBS positioning and communication operators, maps instantaneous thermal map for real-time monitoring and dynamic early warning on the flow of tourists. Forecasting the number of visitors two hours ahead, the Big Data and IoT can help effectively avoiding stampede accident. Application of Big Data and IoT has achieved initial success, however, it is still a long way to go to further enhance the effectiveness of them. On the one hand, the application of Big Data and IoT lies in the integration of multiple data sources, while the Open Government Data in China has not yet started. The other hand, the data collection involves the privacy of tourists, however, the privacy protection mechanism is not perfect. These are the directions for further research. 


\section{Reference}

Ashworth, G., \& Page, S. J. (2011). Urban tourism research: Recent progress and current paradoxes. Tourism Management, 32(1), 1-15. doi:10.1016/j.tourman.2010.02.002

Avraham, E. (2016). Destination marketing and image repair during tourism crises: The case of Egypt. Journal of Hospitality and Tourism Management, 28, 41-48. doi:10.1016/j.jhtm.2016.04.004

Cassedy, K. (1991). Crisis management planning in the travel and tourism industry:A study of three destination cases and a crisis management planning manual. San Francisco: Pacific Asia Travel Association.

Chan, C. S., Nozu, K., \& Cheung, L. T. O. (2019). Tourism and natural disaster management process: perception of tourism stakeholders in the case of Kumamoto earthquake in Japan. Current Issues in Tourism(6).

Chan, C. S., Nozu, K., \& Zhou, Q. (2020). Tourism Stakeholder Perspective for Disaster-Management Process and Resilience: The Case of the 2018 Hokkaido Eastern Iburi Earthquake in Japan. Sustainability, 12.

Chang, G., \& Caneday, L. (2011). Web-based GIS in tourism information search: Perceptions, tasks, and trip attributes. Tourism Management.

Conti, J. P. (2006). The Internet of things. Communications Engineer, 4(6), 20-25.

Estevo, C., \& Costa, C. (2020). Natural Disaster Management in Tourist Destinations: A Systematic Literature Review. European Journal of Tourism Research, 25.

Filimonau, V., \& Coteau, D. D. (2019). Tourism resilience in the context of integrated destination and disaster management (DM2). International Journal of Tourism Research(1).

Gershenfeld, N., Krikorian, R., \& Cohen, D. (2004). The Internet of Things. Scientific American, 291(4), $76-81$.

Gómez Martín, M. B. (2005). Weather, climate and tourism a geographical perspective. Annals of Tourism Research, 32(3), 571-591. doi:10.1016/j.annals.2004.08.004

Goossen, M., Meeuwsen, H., Franke, J., \& Kuyper, M. (2009). My ideal tourism destination: Personalized destination recommendation system combining individual preferences and GIS data. Information Technology \&\# 38; Tourism, 11(1), 17-30.

Gurtner, Y. (2016). Returning to paradise: Investigating issues of tourism crisis and disaster recovery on the island of Bali. Journal of Hospitality and Tourism Management, 28, 11-19. doi:10.1016/j.jhtm.2016.04.007

Ha, K. M. (2020). Mitigating Psychological Impact: The Experience of Korean Disaster Management. Community Mental Health Journal, 1-8.

Hystad, P. W., \& Keller, P. C. (2008). Towards a destination tourism disaster management framework: long-term lessons from a forest fire disaster. Tourism Management, 29(1), 151-162.

J“2nior, C., Rodrigues, R., \& Scoton, G. (2009). Geographic Information System (GIS) as an auxiliary tool for planning and management of tourism in the hydrographic basin the Rio Itaja ${ }^{\cdot a}$ (Santa Catarina). Caderno Virtual de Turismo, 9(1), 63-87.

Jia, Z., Shi, Y., Jia, Y., \& Li, D. (2012). A Framework of Knowledge Management Systems for Tourism Crisis Management. Procedia Engineering, 29, 138-143. doi:10.1016/j.proeng.2011.12.683

Jones, T. E. (2016). Evolving approaches to volcanic tourism crisis management: An investigation of long-term recovery models at Toya-Usu Geopark. Journal of Hospitality and Tourism Management, 28, 31-40. doi:10.1016/j.jhtm.2016.04.005

Kellens, W., Zaalberg, R., Neutens, T., Vanneuville, W., \& Maeyer, P. D. (2011). An Analysis of the Public Perception of Flood Risk on the Belgian Coast. Risk Analysis, 31(7), 1055-1068.

Lee, D. W. (2019). Local government's disaster management capacity and disaster resilience. Local Government Studies(2), $1-24$.

Liu, B., Pennington-Gray, L., \& Krieger, J. (2016). Tourism crisis management: Can the Extended Parallel Process Model be used to understand crisis responses in the cruise industry? Tourism Management, 55, 310-321. doi:10.1016/j.tourman.2016.02.021

Liu, Y., Cheng, P., \& Ouyang, Z. (2019). Disaster risk, risk management, and tourism competitiveness: A cross-nation analysis. International Journal of Tourism Research, 21(6).

Méheux, K., \& Parker, E. (2006). Tourist sector perceptions of natural hazards in Vanuatu and the implications for a small island developing state. Tourism Management, 27(1), 69-85.

Mikulić, J., Sprčić, D. M., Holiček, H., \& Prebežac, D. (2016). Strategic crisis management in tourism: An application of integrated risk management principles to the Croatian tourism industry. Journal of Destination Marketing \& Management.

Orchiston, C. (2012). Seismic risk scenario planning and sustainable tourism management: Christchurch and the Alpine Fault zone, South Island, New Zealand. Journal of Sustainable Tourism, 20(1), 59-79.

Oroian, M., \& Gheres, M. (2012). Developing a risk management model in travel agencies activity: An empirical analysis. Tourism Management, 33(6), 1598-1603. doi:10.1016/j.tourman.2011.12.020

Paraskevas, A., \& Altinay, L. (2013). Signal detection as the first line of defence in tourism crisis management. Tourism Management, 34, 158-171. doi:10.1016/j.tourman.2012.04.007 
Racherla, P., \& Hu, C. (2009). A Framework for Knowledge-Based Crisis Management in the Hospitality and Tourism Industry. Cornell Hospitality Quarterly, 50(4), 561-577. doi:10.1177/1938965509341633

Ritchie, B. W. (2004). Chaos, crises and disasters: a strategic approach to crisis management in the tourism industry. Tourism Management, 25(6), 669-683.

Rittichainuwat, B. (2011). Ghosts: a travel barrier to tourism recovery. Annals of Tourism Research, 38(2), 437-459.

Shurland, D., \& Jong, P. d. ( 2008). Disaster Risk Management for Coastal Tourism Destinations Responding to Climate Change: A Practical Guide for Decision Makers. Retrieved from

Stanganelli, M. (2008). A new pattern of risk management: The Hyogo Framework for Action and Italian practise. SocioEconomic Planning Sciences, 42(2), 92-111. doi:10.1016/j.seps.2006.10.001

Tsai, C. H., \& Chen, C. W. (2011). The establishment of a rapid natural disaster risk assessment model for the tourism industry it. Tourism Management, 32(1), 158-171.

Wang, F. X., Yao, F., Chen, Y. L., \& Chen, C. (2011). Monitoring Study on the Influence of Hainan International Tourism Island Construction to the Mangrove Forest Based on RS and GIS. Advanced Materials Research, 187, 33-38.

\section{Declaration of Conflicting Interests}

The author(s) declared no potential conflicts of interest with respect to the research, authorship, and/or publication of this article.

\section{Funding}

The author(s) disclosed receipt of the following financial support for the research, authorship, and/or publication of this article: This study was supported by a grant from the Guangzhou Huashang College(No.2018HSXS12, to Lijuan Zhang). 